\title{
EL ATRIUM EN LAS VITAS SANCTORUM PATRUM EMERETENSIUM. ¿UNA FÓRMULA DE LA LLAMADA ARQUITECTURA DE PODER?
}

\author{
P()R \\ CRISTINA GODOY FERNÁNDEZ Y FRANCESC TUSET BERTRÁN \\ Unisersidad de Barcelona
}

En homenaje al Prof. Pere de Palol

\section{RFSUMEN}

En este trabajo pretendemos delimitar el significado del término atrium en las l'itus Sanctorum Patrum Emeretensium. C'reemos que «atrium" es utilizado por el opúsculo emeritense con un sentido muy preciso que no se corresponde con la vaguedad de lo que habitualmente el lenguaje arquitectónico expresa con este término. Recabando en esta fuente, intentamos demostrar que la forma y función de este edificio se corresponden con una förmula arquitectónica de poder, en la Mérida de mediados del siglo vil. La comparación con las Etimologias de San Isidoro demuestra que el discurso no es exclusivo de Mérida, sino que atrium es considerado en la Hispania visigoda como una fórmula arquitectonica áulica. adoptada por el poder religioso.

\section{SUMMARY}

In this work we pretend to delimitate the meaning of the term atrium in Vitas Sanctorum Patrum Emeretensium. We believe that "atrium" is used by the brief treatise of Mérida with a very precise meaning that does not correspond with the vagueness of what the architectural language usually expresses with this term. Using this font, we try to prove that the form and function of this building correspond to an architectural formula of power, in the Mérida of about the middle of the VIlth century. The comparison with the Etymologies of Saint Isidore proves that the discourse is not exclusive of Mérida, but rather that atrium is considered in the Visigothic Hispania as a aulic architectural formula, adopted by the religious power.

Las Vitas Sanctorum Patrum Emeretensium es un opúsculo anónimo, escrito en los años treinta del siglo vII, cuyo tema es el relato de la vida y milagros de los obispos emeritenses que ocuparon la sede en la centuria precedente. Existen varias ediciones de este texto, pero nosotros utilizamos la edición critica de A. Maya Sánchez por considerarla la más adecuada '. La obra es de un inestimable valor, no sólo para el conocimiento de los fastos episcopales emeritenses y de la vida religiosa y litúrgica de la sede de Mérida durante esta época, sino también para el desarrollo histórico de la Península durante los reinados de Leovigildo y Recaredo, incluyendo la conflictiva rebelión de Hermenegildo.

Las V.S.P.E. son una fuente de documentación importante para la reconstrucción de los escenarios arquitectónicos, tanto civiles como religiosos, asi como para el estudio topográfico de Mérida en el siglo vi. Ya R. Puertas Tricas la utilizó en su glosario de términos arqueológicos de los testimonios literarios hispánicos ${ }^{2}$. El conocimiento arqueológico de Mérida en época tardorromana y visigoda ha experimentado un gran adelanto en estos últimos años, debido a las excavaciones efectuadas en la iglesia de Santa Eulalia y en la barriada de Santa Catalina, dirigidas por L. Caballero y P. Mateos ${ }^{3}$.

${ }^{1}$ Sobre las ediciones de las Vitas Sanctorum Patrum Emeretensium, efr. Maya Sánchę, A.: Vitas Sanctorum Patrum Emeretensium, C' C. series latina, CXVI, Brepols, Turholt, 1992. Vease tambièn la introducción de (amacho, A.: El lihro de las Vidas de los Santos Padres de Merida. Opaisculo anonime del siglo tut. Estudio. texto latino, versión española, anotaciones y apéndice's documentales. Mérida, 1988, págs. 18-23. Resulta muy útil la obra critica de Garvin, J. N.: The Vitas Sanctorum Patrum Emeretensium. Text and translation with an introduction and commentary, Washington, 1946; aunque nosotros utilizamos la edición critica de Maya Sánchez, cit., por considerar que ha superado las precedentes. La fecha de la composición del texto ha de fijarse en el pontificado de Esteban I, entre el 633 y el 638. A partir de ahora citaremos V.S.P.E.

${ }^{2}$ Puertas Tricas, R.: Iglesias hispánicas (siglos $1 \mathrm{r}$ al vmil). Testimonios literarios. Madrid. 1975, págs. 86-87.

${ }^{3}$ Algunos artículos, de carácter general, en Actas del Simposio Internacional conmemorativo del Bimilenario de Mérida (16 al 20 de noviembre de 1975). Augusta Emerita, Madrid, 1976. Co- 
En este trabajo pretendemos delimitar el significado del término atrium en las I.S.P.E. Creemos que atrium es utilizado en el opúsculo emeritense en un sentido muy preciso que no se corresponde con la vaguedad de lo que habitualmente el lenguaje arquitectónico actual expresa con este término. Arquitectos, arqueólogos e historiadores del arte utilizan el sustantivo "atrium» para referirse a un ámbito descubierto, situado delante de la fábrica de un edificio, más o menos amplio, con distintas soluciones de planta y que puede tener, en alguno o todos sus lados, columnas o pilares sosteniendo cubiertas.

La mejor manera de abordar su significado en las V.S.P.E. es el análisis de las pericopas en las que este término aparece citado y que permiten discutir sobre su ubicación, forma y función.

Conocemos el emplazamiento topográfico del atrium dentro de las murallas de Mérida, por el episodio que narra la vuelta del obispo católico Masona a ocupar la cátedra de Mérida que le habia sido arrebatada por el obispo arriano Sunna. Masona se habia refugiado en la basilica de Santa Eulalia, que se hallaba extramuros, y se dirige al atrium -intramuros-en una solemne procesión por las calles de la ciudad, conforme a su dignidad:

"Accepta igitur sanctus Masona auctoritate eum illico de basilica egredi, ad suum conspectum uenire precepit et, ut semper pietatis

\footnotetext{
Ilins, R.: Merida and Toledo: 550-580, Visigothic Spain, new approaches, Oxford, 1980. Ftienne, R: Merida, capitale du vicariat des Espagnes, Homenaje a Säenz de Buruaga. Madrid. 1982, págs. 201-207. Arce, J: Mérida tardorromana (284-409). Ibidem, págs. 209-226. Allvarez Martinez, J. M.: Excavaciones en Augusta Emerita, Arqueologia de las ciudades modernas superpuestas a las antiguas, Madrid, 1985, págs. 37-49. Sobre la publicación de los trabajos arqueológicos en Santa Fulalia, Caballero Zoreda, L., con la aportación de Mateos Cruz. P.: ¿Visigodo o asturiano" Nuevos hallazgos en Mérida y otros datos para un nuevo "marco de referencia" de la arquitectura y la escultura alto-medieval en el Norte y Oeste de la Peninsula Ibèrica, XXXIX Corsi de cultura sull Arte Ravennate e Bizantina. Aspetti e problemi d'archeologia e arte in Lusitania. Asturia e Galizia tra Tardoantico e Medioevo, Rávena, 1992, págs. 139. 190. Caballero, L. y Mateos, P.: Excavaciones en Santa Eulalia de Mérida, (I Jornadas de Prehistoria y Arqueología de Extremadura, 1986-1990), Extremadura Arqueológica, 2, 1991, págs. 525-546. Íd.: Trabajos arqueológicos en la iglesia de Santa Eulalia de Mérida, (Jornadas sobre Santa Eulalia de Mérida), Extremadura Arqueolígica, 3, 1992, págs. 15-41. Sobre las excavaciones realizadas en la barriada de Santa Catalina, Mateos Cruz, P.: E.l culto a Santa Eulalia y su influencia en el urbanismo emeritense (siglos IV-v1), Extremadura Arqueológica, 3, 1992, págs. 57-79. P. Mateos nos ha comunicado la próxima publicación de su tesis doctoral referente al urbanismo tardorromano de Mérida que sin duda aportará una nueva visión de la Mérida visigoda a partir de las recientes excavaciones y la utilización de las fuentes escritas.
}

uisceribus affluehat. eum blande ne aliquid iam deinceps formidaret admomuit sed ut iussioni principis ohtemperans causa obedientie de eclesia sancte Eolalie usque ad atrium. quod est fundantum intra muros ciuitatis, ante caballum Redempti diaconi pergeret ordinauit. TArreptoquet baculo supradicti diaconi manihusque gestans ad atrium peruenisset, statim eum uir sanctus cum uxore et filiis et omnihus prediis ahsolhens liberum habire permisil" 4 .

Otro párrafo de la misma vida de Masona confirma la ubicación del atrium en el interior de la muralla emeritense:

"Tertio demum die ad atrium, quod est fundatum intra meniis ipsius urbis, repedauit tantaque cum alacritate et mentis constantia regressus est (...)" $)^{5}$.

A pesar de la familiaridad con que el opúsculo emeritense utiliza el término atrium, las descripciones del espacio físico no son muy minuciosas y, por lo tanto, resulta muy dificil intentar reconstruir una planta del edificio o edificios a los que se designa con el sustantivo atrium. En la vida de Fidel, sin embargo, se narra el derrumbamiento del atrium como un fenómeno milagroso, al no producirse ninguna víctima, ocasión que aprovechó el obispo para reconstruirlo en acción de gracias a Dios y a la virgen Eulalia:

"Quodam igitur dominico die, dum in atrium cum multis filiis eclesie resideret, ut mos est, arcidiaconus cum omni clero in albis ab eclesia uenientes coram eo adstiterunt. Moxque ille consurgens, diaconibus ex more turabula gestantes atque ante eum precedentibus, cum uniuersis qui aderant ad eclesiam perrexit, qualiter Deo iubente missarum solemnia celebrarent.

At ubi uniuersi cum eodem de atrio paululum fere decem graduum processerunt foris, ylico ab immis fundamenti omnis repente amplissimi atrii fabrica ruit et neminem ibi oppressit Deo iubente.

Ex qua re pensandum est cuius meriti iste uir fuerit, qui ita apud Deum suis precibus obtinuerit ut prius non daretur antiqui hostis

4 V.S.P.E., V. X1, 104, ed. A. Maya, cit., pág. 91.

s V.S.P.E., V, V, 55-57, ed. A. Maya, cit., pág. 59. 
potestas tante fabrice perpetrare ruinam yuam ipse cunctos foris eductos integro mumero Deo miserante salbaret: sed ut in tanto periculo nullus periret, ob maxime meritis sanctissime uirginis Eulalie fuisse prestitum mullus ambigat.

(...)

Post non multum uero temporis interuallo sedis dirute fabricam restaurauit ac pulcrius Deo opitulante patrauit. Ita nimirum ipsius edificii spatia longe lateque altis culminibus erigens pretiosaque atria columnarum ornatibus suspendens ac pauimentum omne uel parietes cunctos nitidis marmoribus uestiens miranda desuper tecta contexuit»" .

El obispo Fidel se hallaba alli cuando van a buscarlo los miembros del clero para dirigirse a la iglesia en solemne procesión y celebrar la misa; apenas se habian alejado diez pasos de la puerta, el edificio se vino abajo desde los cimientos. El testimonio resulta bastante explicito para asegurar que se refiere a un espacio - al menos en parte-cubierto, con unas puertas de acceso, al que se dirigen en procesión desde la iglesia y del que salen en la misma formación solemne (universi cum eodem [Fidelis] de atrio paululum fere decem graduum processerunt foris). Que no se trata de un simple pórtico podemos inferirlo del verbo que se utiliza-residere-, una voz absolutamente estática que sugiere la espera del obispo sentado (dum in atrium cum multis filiis ecclesiae resideret).

La descripción de la reconstrucción del atrium permite ciertas precisiones sobre el espacio arquitectónico que estamos intentando modelar. La reedificación contemplaba una ampliación en longitud, anchura y altura del edificio; las paredes y el pavimento fueron cubiertos con nítidos mármoles; y los techos fueron recubiertos con un rico artesonado. El autor utiliza el plural de atrium, con un sentido diferente del que aqui venimos analizando (pretiosaque atria columnarum ornatibus suspendens). Es evidente que aqui el plural atria alude a una parte constitutiva del edificio que las V.S.P.E. designan con el singular del mismo sustantivo. En este caso, los atrios de preciosas columnas, han de referirse a los pórticos que forman parte del atrium. Resulta aún más curioso que el autor anónimo del opúsculo emeritense haya escogido el mismo nombre para denominar el atrium y sus pórticos. ¿Tenemos que considerarlo como una coincidencia etimológica

-V.S.P.E., IV, VI, 4-29, ed. A. Maya, cit., págs. 36-38. o, por el contrario, existe alguna otra razón? Volveremos más adelante sobre este asunto.

Sabemos, por el momento, que el atrium es un espacio en parte cubierto y situado cerca de la iglesia, pero lo suficientemente separado de ella como para permitir el despliegue y desplazamiento de la comitiva del obispo en las festividades ordinarias y las solemnes como la de Pascua. La descripción que acabamos de analizar nos lleva incluso a inferir una disposición ortogonal de la planta - cuadrado, rectángulo - al hablarnos de ampliaciones en longitud y en anchura. Pero la verdadera delineación del espacio sigue siendo una incógnita por cuanto no contamos con ninguna descripción más explícita que la arriba citada. Por esta razón vamos a pasar a analizar los textos que refieren la funcionalidad de este espacio, y la disposición de los protagonistas en el escenario; de esta manera podremos averiguar si el atrium requeria un trazado especial en la articulación de su espacio interno.

La utilización más frecuente de este espacio es la de sala de recepción. El obispo recibe a unos mercaderes griegos-negotiatores graecos in navihus de orientibus advenisse atque Hispania litora contigisse-, que al llegar a Mérida van a presentarle sus respetos en el atrium:

"Quumque in Emeretensem ciuitatem peruenissent, ex more episcopo prebuerunt occursum. Qui quum benigne ab eo fuissent recep$t i$ ac de atrio eius egredientes in domum in qua ospitabantur fuissent regressi, (...)")?

El atrium es también el escenario en donde $\mathrm{Ma}$ sona convoca al duque Claudio -dux provinciae ${ }^{*}$ para que actúe de mediador en la disputa por la posesión de Santa Eulalia con el obispo arriano Sunna, quien se habia confabulado con el noble Witerico para dar muerte al obispo católico. Los conspiradores intentaban acceder al atrium y se les prohibe la entrada, quedándose a las puertas del mismo:

"Qui quum uenissent et ingredi ilico voluissent, proibiti sunt et ut paulisper pre foribus expectarent admoniti sunt, quoadusque sanctus Masona ad Claudium uirum clarissimum. ducem Emeritensis ciuitatis, mitteret, ut eo

V.S.P.E, IV, III, 6, ed. A. Maya, cit., pág. 31.

"Cfr. Garcia Moreno, L. A.: Prosopografia del Reino Visigodo de Toledo, Salamanca, 1974, págs. 41-43. Kampers, G. Personengeschichtliche Studien zum Westgotenreich in Spanien. Münster Westfalen, 1979, pág. 127. 
presente se mutuis altornisque cernerent aspectihus. (...).

Quumque eide'm muntianum fuisset, quia domus cius ualde contiguerat atrio, mox cum ingenti multitudine perciter properans udfuit" ".

Con la llegada del duque Claudio, tienen aceeso al atrium tambien los confabulados y el mismo Sunna. Claudio, de rango senatorial, rinde homenaje según costumbre al obispo Masona:

"Denique quum uir inlustris Claudius atrium introisset, protinus et illi qui supra memorati sunt cum ingentibus caterbis populi introierunt ac deinde salutato uiro sancto ex more consederuntm ${ }^{10}$.

Otro episodio nos narra la funcionalidad del atrium como lugar habitual de recepción:

"Qui quum primo diliculo aperta peruenisset ad atrium, protinus eum uir sanctus interrogauit quali ora de predicto loco egressus fuisset»"'.

El adverbio protinus expresa la colocación de uno frente al otro, y sugiere, además, un lugar de preeminencia del obispo, ante el cual el muchacho se presenta.

El atrium es también el lugar donde se desarrolla la disputa entre el obispo Masona y el obispo arriano Sunna en presencia de jueces civiles que actuaban de mediadores. Es preciso subrayar el marcado carácter judicial del acto que se desarrolla en este espacio arquitectónico:

«Ad hec ille [Leuvigildus] talem fertur promulgasse sententiam, ut residentibus in atrio eclesie iudicibus utrique episcopi ab eisdem adsumti adessent ipsisque coram positis utrisque partis defensionem conflictu disputationis altercarent alternisque aduersum se congressionibus dimicantes de sanctarum scripturarum uoluminibus, queque ab eis essent dicta, prolatis testimoniis adstruerent uel roborarent; et cuius pars triumphum brabii obtine-

${ }^{4}$ V.S.P.E., V, X, 27-39, ed. A. Maya, cit., págs. 82-83.

${ }^{10}$ V.S.P.E., V. X, 39, ed. A. Maya, cit., pág. 83. Cabe señalar, en este caso, que el ablativo salutato uiro implica una posición solemne del obispo dentro del atrium y el adverbio ex more nos habla de una ceremonia de salutación reverencial habitual.

"V.S.P.E., IV, VII, 32, ed. A. Maya, cit.., pág. 32 ret. ipse nicilominus eclesiam sancre Eolaliae sihimet uindicaret" ${ }^{\text {? }}$.

El emplazamiento de los personajes sugiere un estrado para la colocación de los jueces, por lo tanto, un lugar de presidencia. Los obispos se colocan uno frente al otro para dirimir las diferencias sobre sus pretensiones acerca de la posesión de la basilica de Santa Eulalia, en pública sesión.

El atrium es también el lugar donde el archidiácono Redempto acude para informarse sobre el estado de salud del obispo Masona, quien ya habia dictado su última voluntad:

"At ubi arcidiacono [Redempto] iam dicto nuntiatum est, ilico atrium petiit, quemammodum haberet sanctus episcopus sciscitauit» ${ }^{13}$.

Se trata del fragmento que relata la premonición de la muerte del obispo Fidel por un devoto de la iglesia de Mérida. Los santos que se hallaban en el coro de la iglesia mandan a unos etiopes para que acaben con los sufrimientos del obispo, pues habia llegado su hora:

"Qui mox sancti dixerunt: "Sub omni celeritate pergentes ad atrium ingredimini cella. in qua sanctus Fidelis episcopus iacet (...) ${ }^{14}$.

Los santos ordenan a los etiopes que se dirijan al atrium y que entren en la habitación del santo obispo. Este párrafo permite dos lecturas. Una, como residencia del obispo - palacio episcopal-en donde se encontraria su habitación; y la otra, como atrium desde el que sería posible acceder a la habitación del obispo, es decir, a su residencia.

En el atrium, Masona reparte vino, aceite y miel a los pobres, actividad que confiere también al edificio un marcado carácter público.

«Si quis uero de ciuibus urbis aut rusticis de ruralibus ad atrium ob necessitate accessisset, licorem uini, olei uel mellis a dispensantibus poposcisset et uasem paruulum in quo lebaret exibuisset et eum uir sanctus uidisset, ut erat semper obtutu gratus, iocundi uultu, mox ipsud uasculum confringi et ut maiorem deferret precipiebat» ${ }^{15}$.

\footnotetext{
12 V.S.P.E., V, V, 42, ed. A. Maya, cit., págs. 58-59

${ }^{13}$ V.S.P.E, V, XIII, 22, ed. A. Maya, cit., pág. 95.

i4 V.S.P.E, IV, IX, 27, ed. A. Maya, cit., pág. 43.

is V.S.P.E., V, III, 27, ed. A. Maya, cit., pág. 51 .
} 
La distribución de vino, aceite y miel por el obispo en Mérida y en estas fechas constituye una institución caritativa eclesiástica que hunde sus raices en una de las funciones más antiguas de las curias municipales romanas: la racionalización de los articulos de primera necesidad entre los más necesitados, los publicani. Resulta ilustrativo que esta función propia de las curias municipales, en Mérida esté asumida plenamente en el siglo vi por la curia episcopal. El ejercicio de las matriculas de los pobres fue la forma más directa empleada por la Iglesia para obtener el favor popular y el medio más seguro para asegurarse el patrocinio sobre la misma ciudad ${ }^{10}$. El escenario para llevar a cabo estos actos - con toda la solemnidad que requieren-es, al menos en lo que a la sede de Mérida se refiere, el atrium.

De las menciones de atrium que hemos recopilado resulta muy difícil definir la forma arquitectónica de lo que las V.S.P.E. conciben como tal. De una lectura superficial del texto podrían desprenderse incluso versiones contradictorias. La mayoria de los autores traducen el término atrium como palacio episcopal ${ }^{17}$. Pero la verdad es que no siempre puede entenderse en este sentido y, máxime, cuando en una ocasión utiliza el sustantivo episcopium para referirse a la residencia del obispo ${ }^{1 x}$.

Otra acepción del término atrium en las V.S.P.E., con un sentido mucho más simbólico, nos clarifica algo más el significado de este concepto arquitectónico en la Mérida de los siglos vi y vII. En IV, IV, 32 , el obispo Paulus abandona el atrium y todos los privilegios de la dignidad episcopal, retirándose a una mísera celda en la basílica de Santa Eulalia: derelinquens atrium et omnia privilegia honoris sui ${ }^{19}$.

\footnotetext{
${ }^{10} \mathrm{Cfr}$. Rouche, M.: La matricule des pauvres, évolution d'une institution de charité du Bas Empire jusqu'à la fin du Haut Moyen Age, Etudes sur I'histoire de la pauvreté. (Moven Age-XV siécle). París, 1974, págs. 83-110. Palol, P. de: Els dipòsits d'àmfores de vi i d'oli en els àmbits basilicals cristians, El vi a l'Antiguitat. Economia, producció $i$ comerş al Mediterrani Occidental. (Badalona, 1985), Badalona, 1987, págs. 419-437. Godoy, C.: Poder i prestigi episcopal en relació al culte de les reliquies dels màrtirs, Homenatge a Miquel Tarradell. Estudis Universitaris Catalans, vol. XXIX, Barcelona, 1993, págs. 889-899.

${ }^{17} \mathrm{Cfr}$. en este sentido Fernández. Alonso, J.: La cura pastoral en la España romanovisigoda, Roma, 1955, p. 82. Puertas Tricas, R., cit. (n. 2), págs. 86-87.

${ }^{10}$ Esto ha llevado a Garvin a concluir que el atrium no era más que una de las habitaciones del palacio episcopal y que, por lo tanto, no puede referirse a la casa del obispo. V.S.P.E., V. XIII, 10, ed. J. Garvin, cit. (n. 1), pág. 252; comentario, pág. 273.

${ }^{19}$ V.S.P.E. IV, IV, 32, De obitu Pauli et Fidelis, ed. A. Maya, cit, pág. 35: "Quem ille id agere proibuit et ut iam deinceps auctoritatem pontificatus sui constanter tenere admonuit atque ut fratrum suorum potius curam ageret imperauit. Ipse uero sanctissimus senex mox derelinquens atrium et omnia priuilegia honoris sui sese ad basilicam sancte Eulalie in cellulam uilissimam contulit».
}

A nuestro entender, atrium es utilizado por el autor del opúsculo en un sentido genérico como atributo de la dignidad episcopal, aunque éste sólo se aplica al obispo ortodoxo Masona y no al obispo arriano Sunna, para el cual sólo se utiliza el término domus para referirse a su residencia. En las V.S.P.E nunca se menciona que Sunna ocupase el atrium, ni aun cuando fue erigido obispo de Mérida por el mismo Leovigildo, aunque, claro está, puede tratarse de una versión algo tendenciosa del mismo cronista. Dificilmente atrium puede significar palacio, en el sentido estricto de la palabra, cuando no es utilizado por las V.S.P.E. para designar la residencia de dos personajes como el duque Claudio - contra el que el autor no siente ninguna animosidad-o el obispo arriano Sunna, como cabria esperarse dado el cargo que desempeñan.

Retornando sobre la ubicación, hemos visto que el atrium se encuentra dentro del recinto murario de la ciudad emeritense. Podemos incluso inferir que su emplazamiento debía estar en el centro neurálgico administrativo de la ciudad, porque en una ocasión se alude a la proximidad de la domus del dux provinciae, Claudio, que, teniendo en cuenta su rango, debia tener el palacio en una ubicación topográfica preeminente ${ }^{20}$.

Una única vez atrium viene determinado por el genitivo ecclesiae ${ }^{21}$. El contexto de la perícopa expresa una orden del rey sobre el escenario en el que debia dirimirse -ante jueces civiles- una causa eclesiástica, como era el litigio entre Masona y Sunna sobre la posesión de la basílica en que se veneraban las reliquias de la mártir Eulalia. En este caso pueden aceptarse dos interpretaciones: una, en la que la sentencia real determine simplemente la naturaleza del espacio en el que debía celebrarse la vista, esto es, en un ámbito eclesiástico ${ }^{22}$; la otra, supondría la

\footnotetext{
${ }^{20}$ V.S.P.E, V, X, 37, "quia domus eius /Claudii] ualde contiguerat atrio(...)", ed. A. Maya, cit., pàg. 83.

${ }^{21}$ Supra, n. 12.

$22 \mathrm{Si}$ aceptamos esta interpretación, debemos pensar que Leovigildo está determinando que la vista se celebre en el atrium de la iglesia por existir, por lo menos, otro bajo su jurisdicción y que el monarca está precisando de esta manera la distinción. Suponiendo que, para los emeritenses, ya sólo existiera el atrium en sentido religioso - el situado intramuros-, es posible que el rey matizara su adscripción con una clara intencionalidad politica: marcar las distancias ante las ingerencias en materia politica de la jerarquia eclesiástica emeritense. En estos momentos, Masona era la única autoridad de la ciudad reconocida por la comunidad cristiana que sólo veia en Leovigildo un monarca impio y hereje. Fl episcopado emeritense, no sólo estaba asumiendo las funciones del poder político, sino que también estaba usurpando -a juicio de la monarquia vísigoda arriana-las formas. V.S.P.E., V, III, 52: "Ita nimirum temporibus eius ditati sunt. ut in diem sacratissimum Pasche, quum ad eclesiam procederet, plurimi pueri cla-
} 
existencia de un atrium en la basílica de Santa Eulalia, al entender el genitivo ecclesiae referido a la iglesia que está en disputa.

Abundando en esta segunda interpretación, en las dos ocasiones en que el autor del anónimo emeritense alude al emplazamiento del atrium en el interior de las murallas de la ciudad - quod est fundatum intra moenia, quod est fundatum intra muros civitatis-, la acción se está desarrollando en la basilica de Santa Eulalia, sita extramuros. Cabe la posibilidad de que el autor considere necesaria esta precisión por existir un atrium en el complejo eclesiástico de Santa Eulalia con funciones análogas a las del atrium situado en el interior de la ciudad.

A nuestro entender, en las V.S.P.E. atrium tiene un significado y unas connotaciones especificas que se alejan, en ocasiones, del sentido clásico y difieren siempre de las varias acepciones que a este término ha dado el lenguaje arquitectónico moderno.

Para la sociedad emeritense del siglo vı y principios del vil parece que el término determina siempre un edificio cristiano; hasta tal punto esto es asi que pasa a ser sinónimo de la dignidad episcopal, como uno de sus atributos más distintivos.

A juzgar por las actividades que tienen por escenario el atrium -audiencias, juicios, reuniones, distribución de matrículas, lugar donde el obispo aguarda con toda solemnidad la procesión que habrá de conducirle hasta la iglesia-, todas ellas con un marcado carácter áulico, y nunca de índole litúrgica, podemos concluir que se trata de un "edificio de representación». En el atrium el obispo de Mérida se manifiesta con toda la majestuosidad, no únicamente la ingénita a su dignidad eclesiástica, sino también y -sobre todo-la inherente a su posición como poder civil. De esta manera se traducía arquitectónica y urbanísticamente la asunción y/o usurpación de las atribuciones que en época imperial eran propias del poder político.

Por estas razones, por lo menos en lo que a Mérida se refiere, este espacio arquitectónico puede equipararse en funcionalidad a las denominadas aulas de recepción emblemáticas de los palacios imperiales y, por delegación, atributo también de la arquitectura de aparato de los praefecti urbium ${ }^{23}$.

mides olisericas induentes quoram eo quasi quoram rege incederent et, quod his temporibus nullus poterat, nullus presummebat, huius indumentis amicti ante eum deuitum deferentes obsequium pergerent", ed. A. Maya, cit,, pág. 53.

${ }^{23} \mathrm{Ya}$ desde la reforma de Constantino los prefectos del pretorio se convirtieron en funcionarios civiles ejerciendo de viceemperadores en las circunscripciones territoriales de las prefecturas. La sede del praefectus urbi disponia de una sala de recepción donde se guardaban los archivos, despachaba el prefecto y se ce-
Resulta comprensible, de este modo, que si alguna vez ha podido interpretarse atrium como sinónimo de palacio episcopal es porque el cronista utiliza este nombre como sinécdoque, es decir, refiriéndose al todo por la parte, al complejo episcopal por el edificio donde se representaba el fasto de su completa autoridad: la religiosa y por ella también la civil o temporal.

No deja de sorprender, sin embargo, que esta fuente literaria sea la única que utilice atrium con este significado. Es evidente que el término debió seguir una evolución semántica desde época clásica y tardorromana, hasta llegar a un período posterior, difícilmente precisable, en el que pasa a designar el pórtico de un edificio ${ }^{24}$.

Isidoro de Sevilla en sus Etimologias nos ofrece una definición de atrium, contemporánea a las V.S.P.E., que, de leerse en el sentido de la interpretación que proponemos, probablemente se ajuste mucho más a la realidad del momento de lo que siempre se ha venido considerando la obra enciclopédica isidoriana:

«Atrium magna aede est, sive amplior et spatiosa domus. Et dictum est atrium, eo quod addantur et tres porticus extrinsecus. Alii atrium quasi ab igne et lychno atrum dixerunt atrum enim fit ex fumo" ${ }^{25}$.

Para Isidoro, atrium es el nombre que recibe un edificio grande y espacioso, una mansión. Hace derivar etimológicamente el nombre de la existencia de tres pórticos adosados por el exterior. Pero lo que resulta realmente interesante es el orden en que figura su definición. Isidoro sitúa el término al principio del capitulo dedicado a las mansiones ( $D e$ habitaculis): primero define aula como «domus est regia, sive spatiosum habitaculum porticibus quattuor conclusum»; en segundo lugar atrium; a continuación añade un comentario sobre el origen ono-

lebraban los juicios. Cfr. Mansuelli, G. A.: La villa e i problemi architettonici, en Garrafo, S. (ed.): La Villa Romana del Casale di Piazza Armerina, Catania, 1984, págs. 84-110.

${ }^{24}$ Du Cange, Glossarium mediae et infimae latinitatis, I, Paris, 1840 , s.v.. Vincent de-Vit, Totius latinitatis lexicon opera et studio, Prado, 1848-1860, s.v.. Maigne d'Arnis, Lexicon manuale ad scriptores mediae et infimae latinitatis, Paris, 1890, s.v.. Cabrol-Leclerq, D.A.C.L., 12, 1, París, 1935, s.v.. Reallexikon für Antike und Christentum, I, Stuttgart, 1950. Delvoye, C.: RzBK, 1, pág. 421, (s.v.). Blaise, A.: Dictionnaire latin-français des auteurs chrétiens, Turnholt, 1954, s.v.. T.L.L., s.v..

${ }^{25}$ Isidoro, Etymologiae, XV, IH, 4, (ed. Oroz Reta, J. y Marcos Casquero, M. A.: San Isidoro de Sevilla, Etimologias, traducción y edición de Lindsay, BAC, $n^{\circ} 433-434$, Madrid, 1982 1983, pág. 234). 
mastıco del vocablo palatium, que hace derivar del principe Palante; siguen por orden thalamum, coenaculum, para llegar a la definición de triclinium, cella, cubiculum y secessus ${ }^{26}$.

Es preciso señalar aqui que Isidoro diferencia de forma muy clara atrium y porticus:

«Porticus, quod transitus sit magis quam ubi standum sit, quasi porta; et porticus, eo quod sit apertus» 27 .

La diferenciación dentro de la terminología isidoriana es triple. Por un lado, porticus es parte integrante de aula y atrium como queda implicito en sus correspondientes definiciones. Esta divergencia conceptual queda, además, manifiesta al incluir porticus en un capítulo diferente (De aditibus) dedicado a las entradas, tras haber concluido la clasificación de los edificios según su función y precediendo, como es lógico, el capítulo titulado De partibus aedificiorum $^{28}$. Por último, la propia definición de porticus señala su carácter de lugar de tránsito y no de permanencia. Para Isidoro, cualquier edificio puede tener porticus mientras que, para alguno de ellos, el número es un elemento definitorio de su categoria y clase dentro de la clasificación establecida por el Hispalense: el aula requiere cuatro portici, el atrium únicamente tres.

La ordenación de Isidoro resulta, a nuestro entender, muy significativa por cuanto relaciona atrium con la edilicia palacial. Pero además, refleja con claridad meridiana la intencionalidad del santo hispalense: una clasificación gradual que parte del aula representativa de la potestad regia con cuatro pórticos, pasando por el atrium que dispone de tres, para acabar con el palatium. Se desprende nitidamente que Isidoro concibe éste último como la residencia real -la parte doméstica-porque su discurso pasa a describir el espacio interior del mismo, espacio interior que, por otra parte, puede ser común con el de las residencias de rango inferior. De esta manera el Hispalense ha definido por lo menos tres edificios independientes en su fábrica y en su función: aula, atrium y palatium. Su discurso sigue un orden

\footnotetext{
${ }^{26}$ Isidoro, Etymologiae, XV, 3, 3-9, ed. Oroz y Marcos, cit.. págs. 234-236.

${ }^{27}$ Isidoro, Etymologiae, XV, 7, 3, ed. Oroz y Marcos, cit., pág. 244 .

${ }^{28}$ Sin duda la traducción literal del título de este capítulo, "Partes que componen un edificio", no se corresponde con el lenguaje isidoriano que, en este caso concreto, es mucho más preciso que el nuestro. En este capitulo, Isidoro hace referencia a los elementos constructivos utilizables en cualquier tipo de edificio, sea cual sea su función.
}

jerárquico según el grado de significación y función política de los edificios. La fórmula arquitectónica que representa la dignidad real es el aula, mientras el palatium es tan sólo la residencia privada del monarca.

Mientras aula y palatium están definidos claramente como edificios aúlicos, no ocurre así con atrium. Su carácter aúlico, dada la coherencia de todo el discurso isidoriano en la cuestión que nos ocupa, debe inferirse por su posición en la enumeración. Siguiendo con este argumento, atrium debe ser un edificio a medio camino entre uno y otro; pero, ¿en qué sentido?

Si cotejamos el modelo que se desprende de las Etimologias y el que se induce de las V.S.P.E., debe descartarse la posibilidad de que el atrium sea simplemente un aula minimizada por la supresión de un pórtico. También ha de desestimarse el atrium como palacio episcopal.

Atrium no está contemplado en el capítulo dedicado a los edificios sagrados, dentro de las Etimologias. Contrariamente a como cabria esperar de la acepción que los especialistas le dan en el Anónimo Emeritense, atrium no es utilizado para denominar el palacio episcopal en la terminología isidoriana. ¿Es que Isidoro no concebía tal proyección edilicia como inherente a la potestad episcopal? ¿O acaso, al haber definido ya el modelo de arquitectura de poder, no lo consideraba necesario? Que la arquitectura cristiana tiene unas connotacionés áulicas para Isidoro puede observarse claramente en la definición que hace del término basilica:

\section{«Basilicae prius vocabantur regum habita- cula, unde et nomen habent; nam "basileos» rex et basilicae regiae habitationes. Nunc autem ideo divina templa basilicae nominan- tur, quia ibi regi omnium Deo cultus et sacri- ficia offeruntur» ${ }^{29}$.}

En la concepción isidoriana de la arquitectura palacial se desprende un esquema triple. El aula es el lugar de representación emblemática de la potestad regia, el palatium, su residencia privada. Del atrium sólo hace una descripción arquitectónica, omitiendo su función.

Al cotejar las V.S.P.E. con las Etimologias resulta que la funcionalidad que desempeña atrium en la edilicia episcopal emeritense no es la especifica de aula ni la de palatium, sino que la complementa en el modelo áulico de arquitectura isidoria-

\footnotetext{
${ }^{29}$ Isidoro, Etymologiae, XV, 4, 11, ed. Oroz y Marcos, cit.,
} págs. 238-240. 
na. Si intentamos buscar los equivalentes de aula y palatium en las V.S.P.E., nos encontramos también con un esquema triple, a la manera isidoriana, pero especificamente eclesiástico.

La función de representación que tiene el aula para la potestad regia halla su análogo en la basilica o el martyrium ${ }^{31}$ - voces que si define Isidoro. como ya hemos visto. Además, en una peculiar ocasión el cronista de las V.S.P.E. utiliza aula en sentido isidoriano:

\section{«Denique prostratis consternatisque uniuer- sis fidei catholice inimicis, sanctus Masona episcopus cum omni plebe sua psalmodie can- ticum exorsus misticas laudes Domino ceci- nit atque ad aulam alme uirginis Eolalie cum omni plebe plaudentes manibus ymnizantes- que uenerunt. Ac deinde Paschalem sollem- nitatem omnes cum eo ciues iucundissime celebrantes more priscorum platearum fra- gore magno iubilantes in laudem Domini clamauerunt dicentes: "Cantemus Domino, gloriose enim honorificatus est»; et iterum: «Dextera tua, Domine, magnificata est in uir- tute; dextera manus tue, Domine, confregit inimicos et pre multitudine magestatis tue conteruisti adversarios» ${ }^{31}$.}

La utilización de aula por el cronista en este fragmento resulta bastante peculiar, porque constituye una excepción al tratamiento habitual que da a la iglesia de Santa Eulalia: basilica y ecclesia. En nuestra opinión, aula tiene aquí una plena acepción isidoriana que puede deducirse del contexto en el que se insiere, a saber, la celebración del triunfo definitivo del catolicismo frente al arrianismo. En Mérida, la celebración de este triunfo no se realizó en la catedral, sino en la iglesia de Santa Eulalia, que, como escenario de tan magno acontecimiento, sólo podía ser vista por el autor como aula.

La funcionalidad de residencia que desempeñaba el palatium para el rey, tiene su equivalente en el episcopium para el obispo.

Si esto es asi, la funcionalidad del atrium isidoriano queda perfectamente ilustrada por su homólogo en las V.S.P.E., un edificio de representación. Queda también fuera de toda duda la adscripción de

\footnotetext{
${ }^{30}$ Isidoro define martyrium a continuación de basilica: «Martyrium locus martyrum Graeca derivatione, eo quod in memoria martyris sit constructum, vel quod sepulchra sanctorum ibi sint martyrum.", Isidoro, Etimologias, XV, IV, 12, ed. Oroz y Marcos, cit., pág. 240.

${ }^{31}$ V.S.P.E., V, XII, 25; ed. A. Maya, cit., págs. 93-94.
}

ambas acepciones de atrium en el modelo de la llamada arquitectura de poder áulico/eclesiástico de este momento.

Por la descripción arquitectónica que nos hace Isidoro, sabemos que el atrium es un edificio majestuoso con tres pórticos. Por otra parte, las V.S.P.E. nos hablan de una funcionalidad de representación del poder que requiere la instalación de un ámbito preeminente para la manifestación del poder del obispo, función ésta que resulta dificil creer que se desarrollara al descubierto. Hemos visto que el Anónimo Emeritense lo define como un edificio en parte cubierto y con atria, por lo que arquitectónicamente el atrium se modela como un complejo con una parte cubierta y -característica ésta definitoria, según el Hispalense- con tres pórticos, que lógicamente deben circunscribir un espacio al aire libre y generar unos ámbitos cubiertos. Del texto emeritense se desprende su emplazamiento próximo a la basílica y en comunicación con las habitaciones privadas del obispo (episcopium) con los que debia constituir un conjunto orgánico.

Por consiguiente, la función de este magno edificio es, ante todo, la concreta y específica de representación del poder, sea real o episcopal. Tanto es asi que las V.S.P.E. Ilegan a identificar atrium como símbolo de los privilegios y dignidad del obispo. En el atrium el obispo ejerce la jurisdicción eclesiástica - episcopalis audientia —, se dirimen causas civiles, se reciben embajadas, se distribuyen matriculas a los pobres; es también donde se reúne la curia episcopal y donde el obispo aguarda la procesión que habrá de conducirle a la iglesia en la festividad solemne de Pascua. En definitiva, es el lugar donde el obispo manifiesta y ejerce el poder y las funciones civiles inherentes a su dignidad.

Por analogía podemos deducir la funcionalidad del atrium que Isidoro definia sólo arquitectónicamente. El atrium isidoriano debía cumplir una funcionalidad similar a la que se desprende del emeritense, la correspondiente a un contexto de poder real. A nuestro entender, debe desempeñar una función de representación del poder fáctico, en cuanto es el escenario donde se realizan las actividades inherentes a la autoridad que representa y que pueden ser delegables. Esta diferenciación contempla una matización muy sutil entre el trono o quien lo ocupa y las funciones intrínsecamente reales pero que pueden ser delegadas.

En conclusión, Isidoro expone el organigrama de la arquitectura aúlica; las V.S.P.E. ilustran su adaptación por el episcopado de Mérida. El Hispalense, sin embargo, no define el organigrama arquitectónico episcopal, porque, a nuestro entender, no lo 


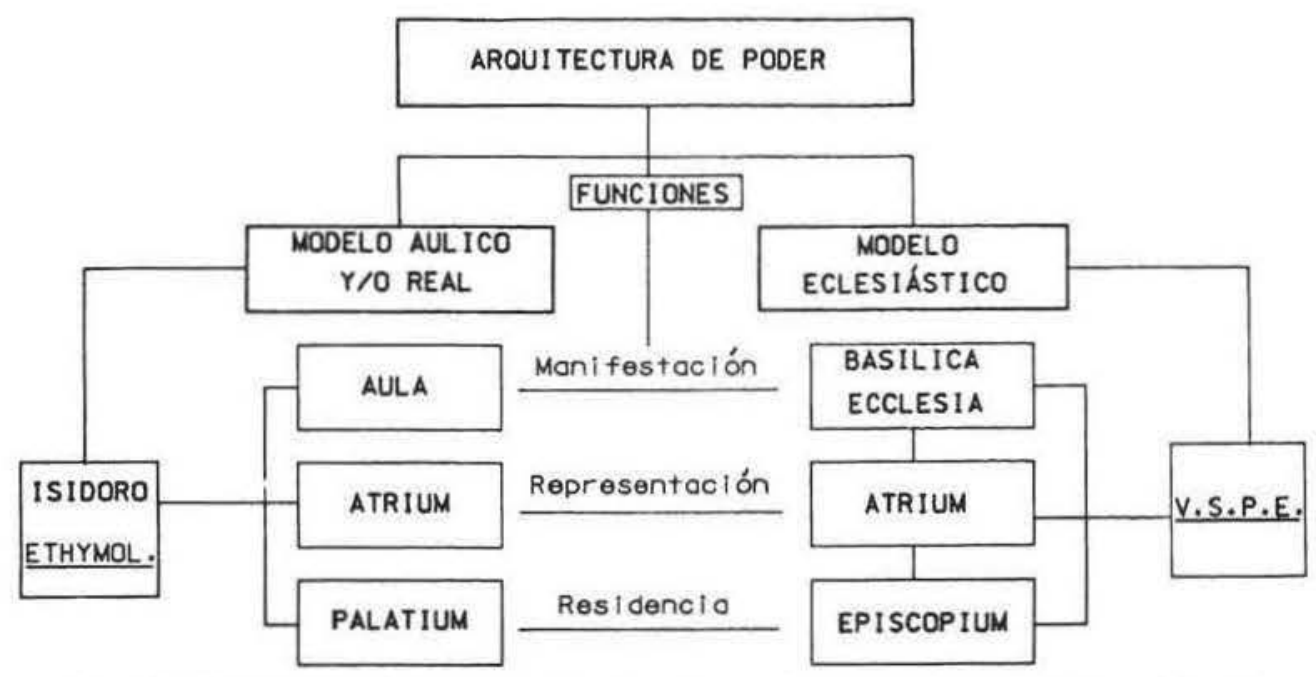

Figura 1.-Organigrama de la arquitectura de poder a partir de las V.S.P.E. e Isidoro de Sevilla.

considera necesario al haber señalado ya el único modelo posible de arquitectura de poder. La utilización de estas fórmulas por el poder eclesiástico le parece a Isidoro del todo justificable, excepto en la fórmula de manifestación; por este motivo introduce la definición de basilica y martyrium en el capitulo dedicado a los edificios sagrados. Es en la voz basilica donde Isidoro precisa esta relación con el aula real: se trata del aula del rey de todos, Dios.

El organigrama isidoriano de la arquitectura de poder y su correspondencia con el modelo eclesiástico de las V.S.P.E. podria ser el de la figura 1.

El estado actual de la investigación arqueológica no permite proyectar, por el momento, esta hipótesis sobre los restos monumentales de Mérida. El conocimiento arqueológico de los conjuntos episcopales del resto de la peninsula Ibérica es, por otra parte, muy fragmentario.

Sin pretender hacer un análisis exhaustivo de los restos de los conjuntos episcopales del orbe cristiano, proponemos algunos ejemplos que ilustran el modelo de arquitectura de poder que venimos definiendo. Nos vamos a ceñir al modelo eclesiástico, por considerar que el áulico merece una atención lo bastante importante como para ser el objeto de un trabajo monográfico futuro.

Entre los conjuntos arqueológicos cristianos conocidos y estudiados, creemos que uno de los ejemplos que más se ajusta al prototipo arquitectónico de atrium que hemos expuesto se halla en el complejo de la iglesia de la Santa Cruz de Rusâfa (Ser- giopolis), en Siria ${ }^{32}$. Rusâfa era, además de un importante centro de peregrinación por la veneración de las reliquias de San Sergio, una destacada sede episcopal. El complejo de la iglesia de la Santa Cruz está constituido por una espaciosa basílica, el martyrion, un edificio absidado en el SE y un gran patio porticado, que Ulbert denomina "Peristylhof», y que es lo que queremos destacar como paradigma ilustrativo de nuestra interpretación de atrium (figura 2).

Este magno espacio porticado se encuentra adosado al muro norte de la iglesia. Su construcción es asociada por Ulbert a la segunda fase constructiva de las cuatro que sufrió el complejo episcopal. La cronologia de estos periodos ha podido precisarse por una superposición de las estructuras a partir del hallazgo de un tesorillo en los niveles fundacionales del primer edificio, datado a finales del siglo $\mathrm{v} e$ inicios del vi. La segunda fase se fecha a mediados del siglo vi, en la que se construye el espacioso patio porticado, bajo los auspicios del obispo Abraham, hacia el $559^{33}$. El tercer momento corresponde a una remodelación que tuvo lugar como consecuencia del destrozo ocasionado por un terremoto en el último cuarto del siglo vi. El peristilo fue reconstruido hacia la década de los ochenta del mismo siglo, en el episcopado de los prelados Sergio y Maronios. La última fase identificada por los excavadores nos

\footnotetext{
12 Ulbert, T: Resafa II. Die Basilika des Heiligen Kreuzes in Resafa-Sergiopolis, Maguncia, 1986. Id.: Resafa-Sergiopoli. XXXV Corso di cultura sull arte Ravennate e Bizantina, (La Siria dal Tardoantico al Medioevo: aspetti e problemi di archeologia e storia dell 'arte), Rávena, 1988, págs. 357-369.

${ }^{3}$ Ulbert, 1986, cit., pág. 148.
} 


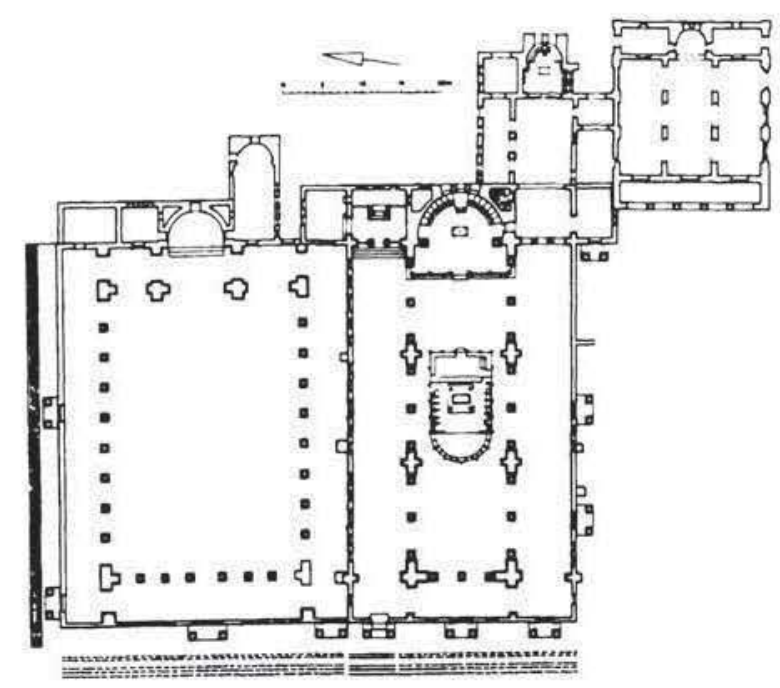

Figura 2.-1glesia de la Santa Cruz de Rusâfa (Siria), segunda fase, según Ulbert.

habla de la amortización funcional originaria de este espacio, puesto que hacia el siglo vII se construye una mezquita, invadiendo la mitad del solar que ocupaba este singular edificio.

El «Peristylhof» del complejo de la iglesia de la Santa Cruz presenta unas características que se acoplan al modelo arquitectónico que hemos establecido a través de Isidoro y de las V.S.P.E.. Constituye un magno espacio descubierto, delimitado por tres pórticos y, en su extremo este, por un complejo de ámbitos cubiertos, entre los que cabe destacar una exedra que coincide, además, con el punto medio de focalización de este edificio. Hay que señalar que la parte este del conjunto se abre al patio con una soberbia fachada con arcos que acentúa aún más si cabe el carácter preeminente de este sector (figura 3 ).

Es interesante apuntar que en la tercera fase constructiva -la efectuada a finales del siglo vi-, tras el terremoto, el «Peristylhof» sufre una transformación en su cabecera, convirtiendo la cámara situada al sur del ábside en un espacio absidado adosado a la exedra, cuya funcionalidad es difícil de precisar por no haberse finalizado su excavación.

Coincidiendo, de esta manera, el "Peristylhof»" de Rusâfa con el edificio modelado teóricamente a través de las fuentes escritas de Isidoro y el opúsculo emeritense, lo proponemos como ilustración arqueológica del atrium. En Rusâfa tenemos el atrium y la basilica-adosados uno a la otra-, faltando por identificar aún el episcopium, del esquema de arquitectura de poder episcopal que hemos propuesto.

Esta proximidad del atrium a la iglesia y al mismo lugar de veneración de las reliquias de San Ser-

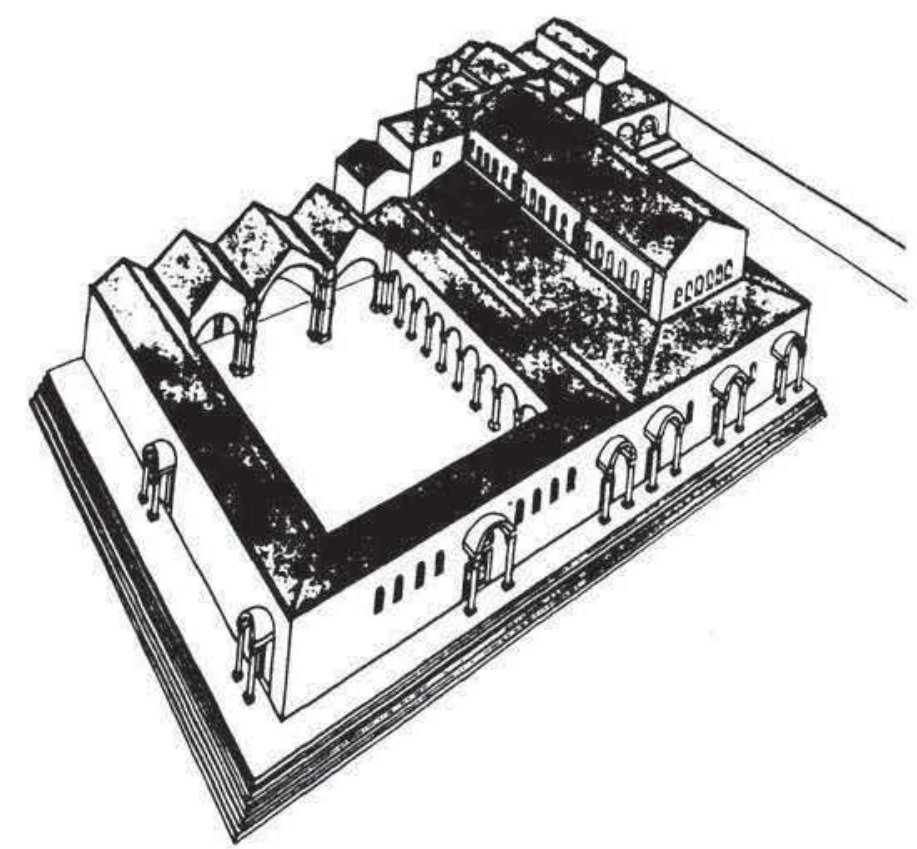

Figura 3.-Alzado de la iglesia de la Santa Çruz de Rusâfa, según Ulbert.

gio no sólo da al conjunto un carácter homogéneo, sino que hace del atrium de la iglesia de la Santa Cruz de Rusâfa el escenario ideal para solemnes procesiones entre este edificio y la iglesia -como las que nos narran las V.S.P.E.-, dada su comunicación directa con el espacio litúrgico de la basílica.

Si aceptamos que el atrium es una fórmula de la arquitectura de poder episcopal, además de la estrictamente áulica, su presencia es imprescindible en los conjuntos catedralicios, o por lo menos un espacio que desempeñe las funciones palatinas concernientes a la episcopalis audientia. La majestuosidad de la construcción dependerá, claro está, de la importancia y de la riqueza de la sede donde se encuentre. En el caso del atrium de Rusâfa, la soberbia construcción y su riqueza decorativa están perfectamente justificadas por la importancia del poder episcopal de un prestigioso centro de peregrinación.

De dar crédito al modelo de la arquitectura de poder isidoriano y al de las V.S.P.E., el atrium es un edificio con entidad propia e independiente. Si bien es cierto que su proximidad a la basilica puede llegar al adosamiento, a juzgar por el caso de Rusâfa.

Sabemos que el atrium es un edificio independiente que no tiene por qué estar adosado a una iglesia, sino más o menos cercano a ella. Teniendo en cuenta esta observación, queremos sacar a relucir de nuevo el problema de interpretación funcional en torno a las denominadas "falsas basílicas» 0 "bâtiments à 

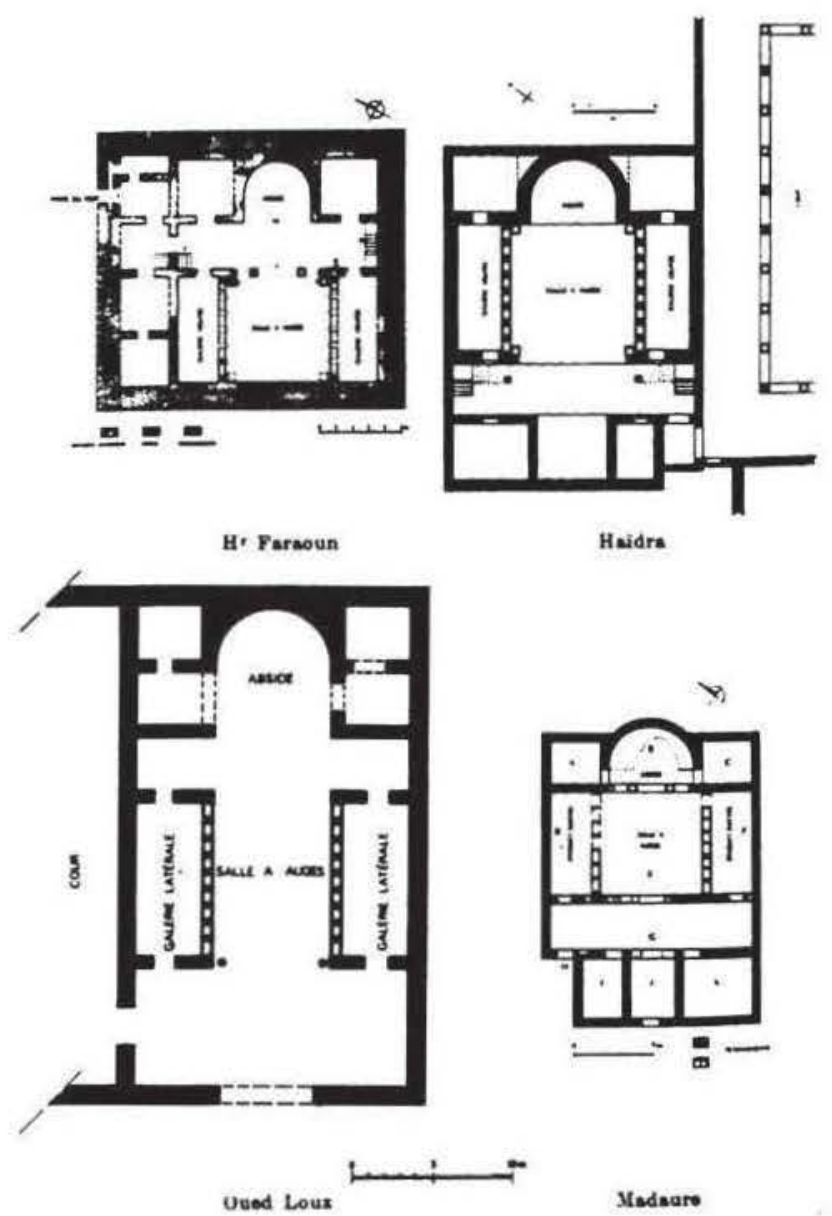

Figura 4.-«Bâtiments à auges» norteafricanos, según Duval.

auges» que en su dia preocuparon a N. e Y. Du$\mathrm{val}^{34}$. En su estudio se analizan cinco monumentos africanos (Hr. Faraoun, Hr. Goubeul, Oued Louz, Haïdra y Madaura), de los que sólo tres han sido excavados (figura 4). Duval data estas construcciones a principios del siglo $\mathrm{v}$ por semejanzas de su escultura arquitectónica con la del complejo de $\mathrm{Te}$ bessa, aunque no existen criterios estratigráficos ni de otra indole que confirmen esta datación.

Referente a la utilización de estos edificios, N. Duval declina las hipótesis que los identificaban con cuadras para los caballos, lo que nos parece de una evidencia contundente, habida cuenta del lujo y de la majestuosidad de las construcciones. Por su parte N. Duval relaciona la magnificencia de estos edificios y la disposición de unas estructuras parecidas a los abrevaderos - de ahí la confusión con caballeri-

${ }^{34}$ Duval, N. y Duval, Y.: Fausses basiliques (et faux martyr). Quelques "bâtiments à auges» d'Afrique, M.E.F.R.A., 84, 1972 , págs. 675-719. zas-con la distribución pública de las largitiones, hipótesis que ya habia formulado G. Picard a propósito de un edificio de estas caracteristicas excavado por él en Mactar $^{35}$. N. Duval encuentra, de esta manera, justificable la solemnidad de la arquitectura, tratándose del prestigio del Estado, de la municipalidad o de los evergetas privados. Esta función favoreceria - continúa N. Duval- la circulación de los beneficiarios en la sala descubierta central, garantizaría la reserva de las provisiones (en los pisos superiores) y facilitaria la distribución (en las salas laterales), permitiendo, al mismo tiempo, la presidencia de la ceremonia por el benefactor o por el magistrado en el ábside ${ }^{36}$.

El esquema arquitectónico de estos edificios se ajusta bastante bien al prototipo de atrium que estamos analizando, si bien desconocemos su relación con otras construcciones de su entorno por falta de excavaciones sistemáticas. Están constituidos por una zona descubierta, rodeada por tres pórticos, y con una parte cubierta con un ábside y cámaras adosadas. Si aceptamos la hipótesis interpretativa de N. Duval, tenemos otro punto de coincidencia, también en la funcionalidad, con el atrium emeritense, al ser éste el escenario de las distribuciones caritativas, las matriculas, efectuadas por el obispo Masona.

En cualquier caso, N. e Y. Duval declinan la interpretación de estos edificios como edilicia cristiana, a pesar de la presencia de algunas inscripciones monogramáticas de carácter aclamativo y de dificil lectura como, por ejemplo, la de Hr. Faraoun.

A modo de recapitulación, diremos que el atrium de las V.S.P.E., tantas veces interpretado como palacio episcopal, constituye una pieza arquitectónica muy peculiar en la edilicia de prestigio episcopal de la Mérida de los siglos vi y vil. La comparación con las Etimologias de Isidoro adscribe al atrium dentro de la arquitectura de poder.

La utilización de ambas fuentes nos ha permitido definir un tipo arquitectónico al que le son inherentes unas determinadas funciones propias del poder que representa. El mejor ejemplo arqueológico, más o menos contemporáneo, es el «Peristylhof» de Rusâfa, en Siria, el atrium del conjunto episcopal de la iglesia de la Santa Cruz.

\footnotetext{
15 Picard, G.: Civitas Mactaritana, Karthago, 8, 1957, págs. $137-144$, n. 457.

${ }^{36}$ Duval, N. y Duval, Y.: cit., págs. 708-709.
} 
Sin embargo, cuando se intenta buscar los origenes de este esquema arquitectónico, tenemos que remontarnos doscientos años. Si bien desconocemos el proceso de formación que se siguió hasta llegar al atrium isidoriano, contamos, sin embargo, con un testimonio altamente ilustrativo de finales del siglo IV: Egeria. El itinerario del peregrinaje realizado por esta monja por Tierra Santa entre los años 381 y 386 incluye numerosas alusiones al complejo del Santo Sepulcro de Jerusalén en la descripción de la liturgia estacional desarrollada en aquella ciudad. En la parte del diario de viaje que dedica a la festividad del Viernes Santo se refiere al espacio existente entre el Martyrium y la Anastasis de la siguiente manera:

«At ubi autem sexta hora se fecerit, sic itur ante Crucem, siue pluuia siue estus sit, quia ipse locus subdiuanus est, id est quasi atrium ualde grandem et pulchrum satis, quod est inter Cruce et Anastase. Ibi ergo omnis populus se colliget, ita ut nec aperiri possit» ${ }^{37}$.

El término quasi atrium que emplea Egeria resulta muy revelador para nuestra interpretación del atrium isidoriano. A pesar del salto cronológico y geográfico que supone este testimonio, no debe olvidarse el origen hispánico de Egeria y que su relato está dirigido a sus hermanas de congregación. El problema está en saber cómo ha de interpretarse el adverbio quasi que modifica a atrium y cuáles son las razones por las que Egeria no emplea este sustantivo con toda claridad.

Sin duda, a los ojos de esta peregrina, el edifício que contempla no reúne todas las características que definen el atrium. ¿Pero, cuáles?

Si Egeria tenia el mismo concepto de atrium que más tarde Isidoro recoge en sus Etimologias, puede inferirse su dificultad en describir, con un lenguaje arquitectónico habitual, el edificio existente entre el Martyrium y la Anastasis, los dos escenarios más sagrados del cristianismo.

El conocimiento arqueológico que se tiene del complejo del Santo Sepulcro es muy fragmentario, a pesar de las excavaciones que se han venido desarrollando. En cualquier caso, la crítica arqueológica acepta la existencia de un espacio descubierto entre el Martyrium y la Anastasis, rodeado por tres pórti-

\footnotetext{
${ }^{37}$ Itinerarium Egeriae, 37, 4. (ed. Franceschini, E. y Weber, R.: Itineraria et alia geographica, CC, series latina, 175, Turnholt, 1965, pág. 81. Cfr. la edición critica y traducción catalana de Janeras, S.: Pelegrinatge d'Egèria, Bernat Metge, Barcelona, 1986, pág. 200.
}

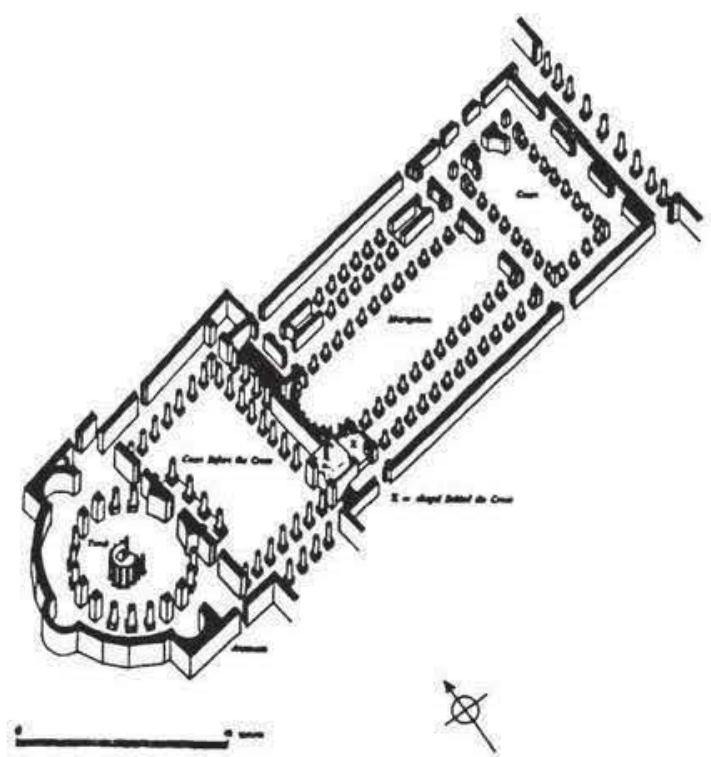

Figura 5.-Reconstruccion del complejo del Santo Sepulcro de Jerusalén, según Wilkinson.

$\cos ^{3 x}$. Aplicando el concepto isidoriano de atrium, cobra significado la descripción del quasi atrium de Egeria la cual justifica, a su vez, la restitución que propone J. Wilkinson (figura 5).

Cuando Egeria se encontraba en el espacio situado entre el Gólgota y el edificio que conmemora la resurrección de Jesús, contemplaría un espacio descubierto rodeado de pórticos -seguramente tres-, pero le faltaba el cuerpo cubierto que Isidoro define como característica propia del atrium que hemos podido restituir en Mérida y podemos observar en Rusâfa. Definir este espacio como atrium habria significado considerar la Anástasis como parte integrante del mismo. Los motivos que hacen que Egeria lo califique como quasi atrium son, entre otros, la veneración que le inspira la propia Anástasis, edificio que tanto arquitectónica como ideológicamente tiene - para la peregrina- una entidad propia. Cabe destacar, por otra parte, que probablemente este es-

${ }^{36}$ Vincent, H. y Abel, F. M.: Jérusalem, recherches et topographie, d'archéologie et d'histoire, Jérusalem nouvelle, II, Paris, 1914, págs. 40-69. Harvey, W.: Church of the Holy Sepulchre Jérusalem. Structural Survey. Final Report, Londres, 1935. Wistrand, E.: Konstantins Kirche am heiligen Grab in Jerusalem nach ältesten litterarischen Zeugnissen, Acta Universitatis Gotoburgiensis, 58, 1952. Conant, K. J.: The original buildings at the Holy Sepulchre, Speculum, 31, 1956, págs. 1-48. Ovadiah, A.: Corpus of the byzantine churches in the Holy Land, (= Theophaneia, 22), Bonn, 1970. Couasnon, Ch.: The Church of Holy Sepulchre in Jerusalem, Londres, 1974. Wilkinson, J.: Egeria's travel to the Holy Land, Jerusalén, 1981. Corbo, V. C.: Il Santo Sepulcro di Gerusalemme, aspetti archeologici dalle origini al periodo crociato, Jerusalén, 1982. ID.: Il santo sepolcro di Gerusalemme. Nova et vetera, $L A, 38,1988$, págs. 391-422. 
pacio que ella califica como quasi atrium desempeǹara funciones intrínsecas del atritum, como parece desprenderse de las procesiones que llevan al obispo hasta este ámbito -definido como ante o post Crucem en el diario de Egeria-, de la misma manera que el obispo emeritense era conducido desde el atrium a la iglesia en las grandes solemnidades. Si esto es asi. podemos entender perfectamente porqué Egeria no estima este espacio - que para ella tendría una función propia- como parte integrante de la Anástasis y opta por llamarlo quasi atrium.

Lejos del sentido habitual que el lenguaje histórico-arquitectónico confiere al atrio como un simple pórtico de un edificio, hemos podido comprobar a través de Isidoro de Sevilla que se trata de una fórmula arquitectónica de poder. Su modelo encaja perfectamente con lo que las I.S.P.E. permiten reconstruir como un edificio de representación del poder episcopal en la Merida de principios del siglo vII.

El concepto de atrium isidoriano halla su representación arquitectónica ideal en el "Peristylhof" de la iglesia de la Santa Cruz de Rusâfa, concepto que volvemos a encontrar en el complejo del Santo Sepulero de Jerusalén y en las "falsas basilicas» norteafricanas.

No queremos acabar sin proponer una reflexion sobre un problema que ha preocupado profundamente a la crítica arqueológica de la Antigüedad Tardia: la interpretación de la llamada «arquitectura de poder». Creemos que deberia replantearse a partir del modelo isidoriano la identificación arqueológico-arquitectónica y la plasmación plástica en las representaciones iconográficas de este tipo de arquitectura. 